\title{
Concentration of chromosomal aberrations on chromosome 3 of Drosophila nasuta
}

\author{
A. KUMAR \& J. P. GUPTA* \\ Department of Biological Sciences, University of Notre Dame, Notre Dame, U.S.A. and *Center of Advanced Study in \\ Zoology, Benaras Hindu University, Varanasi, India
}

\begin{abstract}
Drosophila nasuta harbours a total of 85 inversions in its natural populations. Among them, eight inversions are distributed on the $\mathrm{X}$ chromosome, 24 are located on chromosome 2 and the remaining 53 are concentrated on chromosome 3 . In order to test the possibility of chromosome 3 being intrinsically more vulnerable to breakage in this species, an irradiation study was carried out on the mitotic chromosomes of the neural cells. The results show random distribution of induced aberrations among the $\mathrm{X}$ chromosome, chromosome 2 and chromosome 3 , which suggests that these chromosomes of $D$. nasuta have similar radiosensitivity.
\end{abstract}

Keywords: Drosophila nasuta, concentration of inversions, X-ray-induced aberrations.

\section{Introduction}

Natural populations of many Drosophila species are often polymorphic for chromosome inversions (Lemeunier et al., 1986). Inversion polymorphism in Drosophila is maintained by selective superiority of inversion heterozygotes (Dobzhansky, 1970; Sperlich \& Pfriem, 1986). Based on the distribution pattern of inversions among different chromosomes, three categories have been recognized: (i) species in which the gene sequences are extremely stable showing very few or no inversions; (ii) species in which inversions are about equally distributed among different chromosomes; and (iii) species in which there is a marked concentration of inversions on a particular chromosome (Ward, 1952). The species which show the last category of pattern include $D$. kohkoa (Mather \& Thongmeearkom, 1973), D. nebulosa (Pavan, 1946), D. tetrachaeta (Angus, 1968), D. athabasca (Novitski, 1946), D. melanica (Ward, 1952), D. pseudoobscura and $D$. persimilis (Dobzhansky, 1944), D. guaramunu (Salzano, 1954), D. bocainensis (Carson, 1954), D. paramelanica and D. euronotus (Stalker, 1960, 1964), and D. jambulina (Singh \& Gupta, 1980).

Drosophila nasuta is a member of the immigrans species group of the subgenus Drosophila and is distributed in several countries of south-east Asia and Africa (Kitagawa et al., 1982). The chromosome com-

Correspondence: Dr A. Kumar. Department of Biological Sciences, University of Notre Dame, Notre Dame, In 46556, U.S.A. plement of this species consists of four pairs of chromosomes: a pair of metacentrics (chromosome 2), a pair of large rods (chromosome 3 ), a pair of dots (chromosome 4) and a pair of small rods representing the $\mathrm{X}$ chromosomes while the $\mathrm{Y}$ chromosome is submetacentric (Kumar \& Gupta, 1988). Cytologically, the species is highly polymorphic and harbours a total of 85 inversions and three chromatin band deletions in natural populations examined across its distribution range (Rajasekarasetty et al., 1979; Wakahama \& Kitagawa, 1980; Kumar \& Gupta, 1986a,b, 1988). Of 85 inversions detected, eight are on the $\mathrm{X}$ chromosome, 24 are on chromosome 2 , and the remaining 53 are concentrated on chromosome 3 (Kumar \& Gupta, 1986a, 1988). Moreover, only three inversions, IIL-2 on the left arm of chromosome 2 and III-2 and III-35 on chromosome 3 , are shown to be heterotic in both laboratory and natural populations of the species (Kumar \& Gupta, 1988, 1989).

In order to test whether chromosome 3 of $D$. nasuta is intrinsically more vulnerable to breakage, an irradiation study was performed on the third instar larvae with different doses of X-rays and their neural cells were scored for different types of aberration on each chromosome. This method of Gatti et al. (1974) has an advantage over others, in which genetic damage has been analysed in the $F_{1}$ generation, in that the genetic damage can be easily assessed in the same generation. Moreover, there is a little or no chance of the genetic damage remaining undetected by this method unlike others in which inviability of gametes will give failure of 
detection in the $F_{1}$ generation. An analysis of variance (ANOVA) was carried out to test if there was a marked concentration of breaks on chromosome 3 or if the breaks were randomly distributed among the $\mathrm{X}$ chromosome, chromosome 2 and chromosome 3.

\section{Materials and methods}

In all the irradiation experiments performed, third instar larvae were obtained from a laboratory stock of $D$. nasuta. The stock was founded by a single naturally inseminated female collected from the Botanical Garden on the Benaras Hindu University campus. The cytological analysis of the polytene chromosomes of third instar larvae from this stock showed that the larvae were homozygous for standard gene arrangements on all the chromosomes.

Mitotic chromosome preparations were made from the neural cells. A group of third instar larvae containing a similar number of males and females of about similar age were placed in a plastic Petri dish with blotting paper soaked in insect saline $(0.67$ per cent solution of $\mathrm{NaCl}$ ) on its bottom. Larvae were irradiated with either $625 \mathrm{rad}$ or $1250 \mathrm{rad}$ of X-rays $(110 \mathrm{kV}$, $4 \mathrm{~mA}, 1 \mathrm{~mm}$ aluminium filter, $10 \mathrm{~cm}$ distance, $420 \mathrm{rad}$ $\min ^{-1}$ by the Picker's X-ray machine). Larvae in the Petri dish were divided into two groups. Larvae in one group were immediately dissected in Poels' salt tissue culture medium (Mukherjee \& Lakhotia, 1981) for brain ganglia which were then treated with $1 \mu \mathrm{g} \mathrm{ml}^{-1}$ of colchicine for $1 \mathrm{~h}$ and $25 \mathrm{~min}$. The brain ganglia were transferred to a hypotonic solution $(0.67$ per cent solution of tri-sodium citrate) for $35 \mathrm{~min}$ before fixing in aceto-methanol (1:3) for $15 \mathrm{~min}$ with three changes of $5 \mathrm{~min}$ each. The brain ganglion from each larva was teased out in a drop of 60 per cent acetic acid on a warm slide to facilitate the dissociation of neural cells. These cells were later fixed on the same slide by adding a few drops of fixative and the slide was air-dried $(2 \mathrm{~h}$ of the post-irradiation time of fixation). Larvae in the second group were dissected in Poels' salt tissue culture medium after $2 \mathrm{~h}$ of irradiation and processed as described above $(4 \mathrm{~h}$ of the post-irradiation time of fixation). The air-dried slides were stained in a 5 per cent Giemsa and examined for different types of aberration. The final data concerning the type and frequency of chromosome aberrations were obtained by adding together many partial data, and not more than 10 metaphase plates were scored from each larva.

\section{Results}

A thorough analysis of a large number of irradiated cells revealed various types of induced chromosome
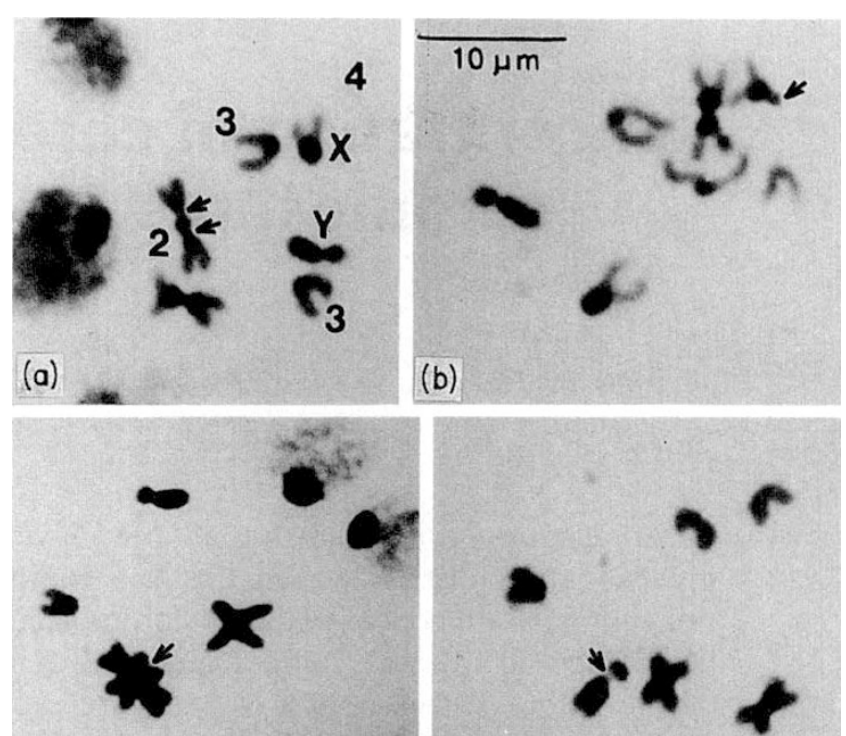

(c)
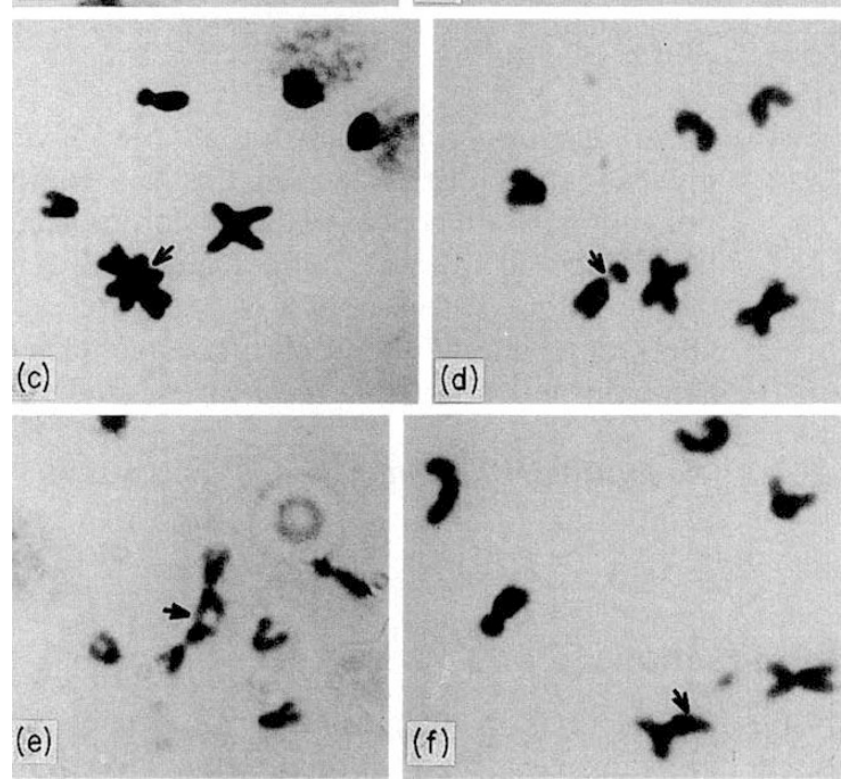

Fig. 1 X-ray-induced aberrations in mitotic chromosomes of the neural cells of Drosophila nasuta (see arrows): (a) (o') dicentric in chromosome $2 ;(b)\left(\delta^{\prime}\right)$ chromosome break at the centromere of chromosome 2 ; (c) ( $\left.\sigma^{\prime}\right)$ symmetrical chromatid exchange between both homologues of chromosome $2 ;(d)$ (ठ) chromosome break at the centromere of the Y chromosome; (e) (o') Asymmetrical chromatid exchange between both homologues of chromosome 2; and, (f) ( $\sigma^{\prime \prime}$ ) chromatid deletion in chromosome 2 .

aberrations. These aberrations were chromatid deletions, chromatid gaps, chromosome deletions, chromosome gaps, isochromatid deletions, chromosome exchanges and discentrics. Some of the examples are shown in Fig. 1. Data on chromatid deletions and chromatid gaps were pooled together. Similarly, chromosome deletions, chromosome gaps and isochromatid deletions were pooled together. Frequencies of the different types of aberration are not presented here but may be obtained upon request. Table 1 gives the total number of breaks among different chromosomes. The observations clearly show that the sexes had different radiosensitivity. The males show a higher number of breaks than the females at each dose of $\mathrm{X}$-rays and post-irradiation time of fixation. The $\mathrm{Y}$ chromosome was found to be more resistant to breakage, and the 
Table 1 Total number of X-ray-induced breaks $\dagger$ on the different chromosomes in the neural cells $\ddagger$ of Drosophila nasuta

\begin{tabular}{|c|c|c|c|c|c|c|c|}
\hline \multirow{2}{*}{$\begin{array}{l}\text { Dose } \\
\text { (rad) }\end{array}$} & \multirow{2}{*}{$\begin{array}{l}\text { Post-irradiation } \\
\text { time of fixation } \\
\text { (h) }\end{array}$} & \multirow[b]{2}{*}{ Sex } & \multicolumn{4}{|c|}{ Chromosomes } & \multirow[b]{2}{*}{$T \S$} \\
\hline & & & $\mathrm{X}$ & $Y$ & 2 & 3 & \\
\hline \multirow{2}{*}{ Control } & \multirow[t]{2}{*}{0} & 우 & 0 & 0 & 0 & 0 & 0 \\
\hline & & రేర & 0 & 0 & 0 & 0 & 0 \\
\hline \multirow[t]{4}{*}{625} & \multirow[t]{2}{*}{2} & $\% \pi$ & 10 & 0 & 5 & 12 & 27 \\
\hline & & రేరేा & 14 & 7 & 36 & 26 & $83^{* *}$ \\
\hline & \multirow[t]{2}{*}{4} & ○९ा & 12 & 0 & 8 & 8 & 28 \\
\hline & & రొరేగ & 13 & 0 & 22 & 16 & $51^{*}$ \\
\hline \multirow[t]{4}{*}{1250} & \multirow[t]{2}{*}{2} & $९ \pi$ & 40 & 0 & 17 & 24 & 81 \\
\hline & & రేరిగ & 65 & 6 & 41 & 47 & $159^{* *}$ \\
\hline & \multirow[t]{2}{*}{4} & ஜำ & 25 & 0 & 32 & 16 & 73 \\
\hline & & 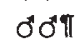 & 44 & 1 & 70 & 56 & $171^{* *}$ \\
\hline
\end{tabular}

$\dagger$ Total number of breaks included all types of aberrations: chromatid and chromosome breaks were considered as a single event; exchanges and dicentrics were considered as two events.

$\ddagger$ A total of 200 mitotic cells were scored for each sex at each time. The same number of cells was scored for each sex of the control.

$\S$ Total number of breaks.

TNot significant at $P<0.05$. The $\mathrm{Y}$ chromosome is excluded from the statistical analysis because it is embedded in the chromocentre of polytene chromosomes and, therefore, spontaneous aberrations cannot be recorded on it in natural populations of $D$. nasuta.

*Significant in $\chi^{2}$ test, $P<0.05$.

**Significant in $\chi^{2}$ test, $P<0.01$.

breaks were preferentially localized on the $\mathrm{X}$ chromosome and on the autosomes (chromosome 2 and chromosome 3 ). The analysis of variance was carried out for each time and the dose of X-rays in males and females separately among the $\mathrm{X}$ chromosome and the autosomes. The analysis showed that the aberrations were distributed at random among the chromosomes, indicating that these chromosomes of $D$. nasuta had similar radiosensitivity.

\section{Discussion}

Two hypotheses, the mechanical hypothesis of Novitski (1946) and the co-adaptation hypothesis of Wasserman (1963), have previously been given to explain the concentration of inversion break points on a specific chromosome. According to the mechanical hypothesis of Novitski (1946), because of the formation of a reversed loop in cells of inversion heterozygotes with an asynaptic region at the ends of the inverted section, one inversion would tend to lead to the formation of others with closely similar break points. Although this hypothesis obtained some support from an irradiation study carried out by Bernstein \& Goldstein (1961), it has been rejected by several others on the grounds that spontaneous aberrations are far too common (White, 1973). The mechanical hypothesis would seem possible if the frequencies of spontaneous aberrations (rearrangements) were very low, so that non-randomness in their occurrence would play a significant role in determining the concentration of break points on a particular chromosome (White, 1973). On the other hand, if the spontaneous rearrangements are common (of the order of 1 per 1000 gametes) then it appears more likely that the final picture would be determined by natural selection (White, 1973). Studies in several animals have shown that spontaneous rearrangements are indeed far more common (White, 1973). Spontaneous rearrangements are also quite common in $D$. nasuta (Kumar \& Gupta, 1988). The evidence thus appears to favour the co-adaptation hypothesis of Wasserman (1963). According to this hypothesis, a marked concentration of inversions on a specific chromosome in some species would be a consequence of the genetic make-up rather than due to a chain reaction depending on an initial rearrangement, as proposed by Novitski (1946). The concentration of inversions on a specific chromosome is the result of natural selection. Inversions occur with an approximately equal frequency in other chromosomes but they are eliminated by natural selection (Wasserman, 1963). . In the case of $D$. nasuta, of 53 inversions concentrated on chromosome 3 , only two, III-2 and III-35, coexist with the species and the rest are detected in a single or in a few individuals and/or populations (Kumar \& Gupta, 1988). Moreover, these two inversions have been shown to be heterotic in both natural and laboratory populations of $D$. nasuta (Kumar \& Gupta, 1988, 1989). These observations suggest that only these two inversions are favoured by natural selection. Therefore, the concentration of inversions on chromosome 3 of $D$. nasuta is not the result of natural selection.

The present result has clearly shown that males have higher radiosensitivity than females. This is in contrast to the finding of Gatti et al. (1974) in D. melanogaster. However, the present result is in agreement with reports for the muntjac, Muntiacus muntjak (Das \& Sharma, 1981). Although the exact mechanism for differential radiosensitivity of the sexes is not yet known, Gatti et al. (1974) and Das \& Sharma (1981) suggested that differential radiosensitivity of the sexes may be due to differential DNA repair efficiency and/ or other intrinsic factors. As in D. melanogaster (Gatti et al., 1974), the $\mathrm{Y}$ chromosome of $D$. nasuta was also found to be highly radioresistant. It may be possible 
that the factors such as the different protein composition or the coiling of DNA play a significant role in determining the radioresistance of the entirely heterochromatic Y chromosome of D. melanogaster (Gatti et $a l ., 1974$ ) and $D$. nasuta. In spite of the preferential localization of breaks on the $\mathrm{X}$ chromosome and on the autosomes (chromosome 2 and chromosome 3 ) in D. nasuta, the statistical analysis shows that the breaks are randomly distributed among these chromosomes at each dose of X-ray and post-irradiation time of fixation.

The random distribution of X-ray-induced aberrations among the $\mathrm{X}$ chromosome and the autosomes observed in the present study does not support our hypothesis that chromosome 3 in $D$. nasuta is intrinsically more vulnerable to breakage. In view of the present finding, it appears difficult at present to understand the mechanism that may be responsible for the concentration of inversions on chromosome 3 of $D$. nasuta. Recently, Lemeunier et al. (1986) suggested that the concentration of inversion break points on a specific chromosome reflects two quite different processes, non-random occurrence and non-random survival. The non-random occurrence (concentration) of inversion break points may be largely due to a secondary consequence of the distribution of transposable genetic elements (Engels \& Preston, 1981). If the concentration of inversion break points results from the effect of transposable genetic elements then the occurrence of inversions will be affected by the abundance and distribution of these elements on a specific chromosome (Lemeunier et al., 1986). Based on their work in D. melanogaster, Yamaguchi et al. (1976) suggested that natural populations contain factors that may influence the rate of occurrence of inversions and the concentration of inversions on specific chromosomes. Furthermore, they suggested that these factors may have properties to transpose. We suggest that further molecular studies are needed for the isolation and then the mapping of these elements through the use of in situ hybridization to the polytene chromosomes of $D$. nasuta to elucidate this possibility.

\section{Acknowledgements}

This work was financially supported by a Senior Research Fellowship to AK by the Council of Scientific and Industrial Research, New Delhi. We thank Dr G. Pasteur, Montpellier, for comments on an earlier draft of the manuscript. We also thank the reviewers for important suggestions.

\section{References}

ANGUS, D. S. 1968. Chromosomal polymorphism in Drosophila tetrachaeta. Am. Nat., 95, 53-56.

BERNSTEIN, N. AND GOLDSTEIN, E. 1961. Chromosomal breakage in structural heterozygotes. Am. Nat., 11, 1-10.

CARSON, H. L. 1954. Interfertile sibling species in the willistoni group of Drosophila. Evolution, 8, 148-165.

DAS, B. C. AND SHARMA, T. 1981. Enhanced frequency of chromosome aberrations in lymphocytes of male compared with female muntjacs after X-ray irradiation in vitro. Nature, 290, 604-607.

DOBZhansKY, TH. 1970. Genetics of the Evolutionary Process. Columbia University Press, New York.

DOBzhansky, тн. 1944. Chromosomal races in Drosophila peudoobscura and Drosophila persimilis. Carnegie Inst. Wash. Publ., 554, 47-144.

ENGELS, W. R. AND PRESTON, C. R. 1981. Identifying P factors in Drosophila by means of breakage hotspots. Cell, 26, 421-428.

GATTI, M., TANZARELLA, C. AND OLIVIERI, G. 1974. Analysis of the chromosome aberrations induced by X-rays in somatic cells of Drosophila melanogaster. Genetics, 77, 701-719.

KITAGAWA, O., WAKAHAMA, K. I., FUYAMA, Y., SHimadA, Y., TAKANASHI, E., HATSUMI, M., UWABO, M. AND MITA, Y. 1982. Genetic studies of the Drosophila nasuta subgroup with notes on the distribution and morphology. Jpn. J. Genet., 57, 113-141.

KUMAR, A. AND GUPTA, J. P. 1986a. Inversion polymorphism in Drosophila nasuta. Dros. Inf. Serv., 63, 78-80.

KUMAR, A. AND GUPTA, J. P. 1986 b. Terminal chromatin band deletions in the polytene chromosomes of Drosophila nasuta. Braz. J. Genet., 9, 539-543.

KUMAR, A. AND GUPTA, J. P. 1988. Genetics of natural populations of Drosophila nasuta. J. Hered., 79, 83-88.

KUMAR, A. AND GUPTA, J. P. 1989. Gene frequencies in natural and laboratory populations of Drosophila nasuta. Hereditas, 110, 1-5.

LEMEUNIER, F., DAVID, J. R., TSACAS, L. AND ASHBURNER, M. 1986. The melanogaster species group. In: Ashburner, M., Carson, H. L. and Thompson, J. R., Jr. (eds) The Genetics and Biology of Drosophila. Academic Press, London, vol. 3e, pp. 147-256.

MATHER, W. B. AND THONGMEEARKOM, P. 1973. The nasuta complex in Luxon. Dros. Inf. Serv., 50, 60-63.

MUKHERJEE, T. AND LAKHOTIA, S. C. 1981. Specific induction of 93D puff in Drosophila melanogaster by a homogenate of heat shocked larval salivary glands. Ind. J. Exp. Biol., 19, $1-4$.

NOVITSKI, E. 1946. Chromosome variation in Drosophila athabasca. Genetics, 31, 508-524.

PAVAN, C. 1946. Chromosomal variation in Drosophila nebulosa. Proc. Nat. Acad. Sci., U.S.A, 32, 137-145.

RAJASEKARASETTY, M. R., RAMESH, S. R. AND KRISHNAMURTHY, N. B. 1979. Inversions in the natural populations of Drosophila nasuta. Nucleus, 22, 92-95.

SALZANO, F. M. 1954. Chromosomal relations in two species of the guarani group of Drosophila. Naturalist, 88, 399-405.

SINGH, B. K. AND GUPTA, J. P. 1980. Pattern of chromosomal 
polymorphism in Drosophila jambulina Parshad and Paika. Jpn. J. Genet., 55, 81-90.

SPERLICH, D. AND PFRIEM, P. 1986. Chromosomal polymorphism in natural and experimental populations. In: Ashburner, M., Carson, H. L. and Thompson, J. A., Jr. (eds) The Genetics and Biology of Drosophila. Academic Press, London, vol. 3e, pp. 257-309.

STALKER, H. D. 1960. Chromosomal polymorphism in Drosophila paramelanica Patterson. Genetics, 45, 95-114.

STALKER, H. D. 1964. Chromosomal polymorphisms in Drosophila euronotus. Genetics, 49, 669-687.

WAKAHAMA, K. I. AND KITAGAWA, O. 1980. The salivary gland chromosomes of Drosophila nasuta. Mem. Soc. Fac. Shiman. Univ., 14, 103-126.

WARD, C. L. 1952. Chromosome variation in Drosophila melanica. Studies in Genetics (Univ. Tex. Publ.), 4228, 23-52.

WASSERMAN, M. 1963. Cytology and phylogeny of Drosophila. Am. Nat., 97, 332-352.

white, M. J. D. 1973. Animal Cytology and Evolution. The Unversity Press, Cambridge, pp. 228-284.

YamaguCHI, O., CARDELlino, R. A. AND MUKaI, T. 1976. High rates of occurrence of spontaneous chromosome aberrations in Drosophila melanogaster. Genetics, 83, 409-422. 